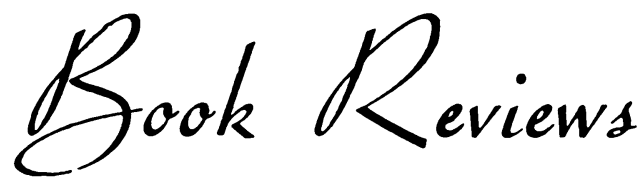

\section{NEUROLOGIC AND PSYCHIATRIC ASPECTS OF THE DISORDERS OF AGEING}

rst edition. Pp. 307, with 79 illustrations. London: Baillière, Tindall \& Cox Ltd. $\quad$ I 956. 68s.

Edited by Drs. J. E. Moore, H. H. Merritt and R. J. Masselink, this is volume 35 of the research -publications of the Association for Research into Nervous and Mental Disease. Previous volumes of the A.R.N.M.D. have been reviewed in these columns and readers of this series will know that they represent the highest standard of medical research and reporting.

It is significant that the topic chosen has been 'ageing ' rather than 'the aged,' typifying the dynamic as opposed to the static approach, since it is the dynamic concept of the problem which has been adopted. Because of this the work has a wide interest throughout medicine and is not merely the concern of specialists in geriatrics and gerontology. As in previous publications, the editorial board has selected contributors (25 in all) from the leading research centres of Canada and the United States, the only extra-American contributor being Macdonald Critchley from Queen Square. The team includes psychologists, psychiatrists, biologists, physiologists, anatomists, geneticists, physicians and specialists from many other disciplines and cooperate in providing a comprehensive attack on the problem from many directions.

There are 15 papers. The first group is concerned with relating ageing to cell and neuron processes, to brain metabolism and cerebral blood flow, to psychopathological and pharmacological effects, and to intelligence and genetic mechanisms. The second selection deals directly with the problems of the elderly patient: epidemiology, neural and vascular changes and rehabilitation. Following the main part of the book comes a panel discussion, in which the eight discussants describe therapeutic measures and the medical management of old people. Breakdown and rehabilitation, problems of retirement and cultural attitudes towards ageing are other subjects which receive full discussion. This panel piece is characterized by clear thinking and a very sympathetic understanding of the needs of the elderly. At a time when life spans are increasing and an ageing population represents a social threat and a medical problem, this authoritative, comprehensive and well-balanced account makes a valuable contribution to medical literature.

\section{PRINCIPLES OF GYNAECOLOGY}

By T. N. A. JEFFCOATE, M.D., F.R.C.S., F.R.C.O.G. Pp. viii $+669+$ index 27 , with 436 illustrations. London: Butterworth \& Co. Ltd. I 957.75 s.

What a joy it is to have a textbook of gynaecology like this. It brings a freshness to the subject that has to be seen to be believed. The book has been aimed at the student at the top of the class. Such is Professor Jeffcoate's skill and so sure his touch as a teacher that by aiming to teach the man at the top of the undergraduate class he also inevitably teaches the student who is only halfway up and even lower; and he also teaches the most mature postgraduate.

Let us take a clinical example, for that is a good way to test a textbook. A case of the relatively rare condition of urethral diverticulum presented itself and I decided to consult the eight popular textbooks of gynaecology of which I have review copies! Only Jeffcoate's gives the condition more than a line or two. He has an illustration-fresh for this book and not rehashed. He gives the causes, diagnosis, complications and treatment all on one beautiful page. The author has purposely considered what he found difficult to understand and to learn, and with an ease of style that speaks of many, many hours of the most careful preparation he has set out to expound, clarify and illustrate so that anyone must learn and want to go on learning the whole subject. The commonplace has not been sacrificed just to expound the rare and difficult.

Ectopic pregnancy, for instance, has 16 pages, including four colour illustrations and ${ }_{1} 3$ in black and white, none of which I had seen before. Again, we find the careful, lucid exposition of orthodox views expounded in an unorthodox way, using all modern techniques of descriptive writing, photography and drawing.

Let us be truly grateful that a man has been able to distil what he has absorbed by reading, by discussion and by clinical knowledge-in short, by his total experience-so that an old subject has a new look more attractive than any presented for many a long day.

Whether the purely physical aspects of gynaecology are the topics, or the psycho-somatic are, as at puberty and the menopause, following hysterectomy, during the treatment for cancer or an early or difficult marriage and in the infertile patient, the teaching is always that of a master. This truly is a book to have and to cherish.

E.E.P. 